\title{
SUSTENTABILIDAD Y COMPETITIVIDAD UN RETO PARA LOS DESTINOS TURÍSTICOS DE SOL Y PLAYA. CASO: RINCÓN DE GUAYABITOS, NAYARIT, MEXICO
}

\section{SUSTAINABILITY AND COMPETITIVENESS A CHALLENGE FOR SUN AND BEACH TOURIST DESTINATIONS. CASE OF RINCON DE GUAYABITOS, NAYARIT, MEXICO}

\author{
María Alicia Fonseca Morales ${ }^{1}$ \\ Ismael Fabricio Puentes Ávila²
}

1, 2 Profesores-Investigadores de la Universidad Autónoma de Nayarit. Cd. de la cultura “Amado Nervo” s/n. CP.63190. Correos electrónicos: afonseca2014@ hotmail.com, fapuentes76@gmail.com

Recibido: 11.12.17 Aprobado: 22.07.18

DOI:10.15517/isucr.v20i41.38778

\section{Resumen}

En México, desde la década de los setentas las zonas costeras han despertado la atracción de los desarrolladores del turismo y así implantar el modelo conocido como destinos turísticos de sol y playa, a ese tipo de emprendimientos se insertó al estado de Nayarit, iniciando por su región costa sur que incluye a Rincón de Guayabitos. Sin embargo, el uso masivo y el escaso cumplimiento de los ordenamientos ambientales que le caracteriza a dicho modelo, ha ejercido excesiva presión en esos importantes ecosistemas de transición marítimoterrestre. Es necesario se reconozca que no todo son grandes volúmenes de visitantes y rentabilidad positiva, el reto está en la concepción de una sinergia sistémica por la sustentabilidad y competitividad de los destinos turísticos, que asegure la conservación de sus recursos base y al mismo tiempo sean productivamente innovadores en servicios de ocio y recreación a efecto de posicionarse entre los mejores estándares de calidad mundial.

Palabras claves: Turismo; Sostenibilidad; México; Competitividad.

\begin{abstract}
In Mexico, since the seventies the coastal areas have aroused the attraction of tourism developers and thus implement the model known as sun and beach tourist destinations, to this type of ventures was inserted to the state of Nayarit, starting with its South coast region that includes Rincon de Guayabitos. However, the massive use and poor compliance with the environmental regulations that characterize this model has exerted excessive pressure on these important maritime-land transition ecosystems. It is necessary to recognize that not all
\end{abstract}


are large volumes of visitors and positive profitability, the challenge is in the conception of a systemic synergy for the sustainability and competitiveness of tourist destinations, which ensures the conservation of their base resources and at the same time be productive Innovators in leisure and recreation services in order to position themselves among the best world quality standards.

Keywords: Tourism; Sustainability; México; Competitiveness.

\section{Introducción}

El turismo en su constante evolución, desempeña un papel cada vez de mayor importancia, se ha convertido en una de las actividades económicas más redituables y de mayor crecimiento a nivel mundial, debido principalmente a nuevas formas de movilidad de la población y la innovación de las tecnologías, hoy es posible mayor tiempo de ocio, costos más accesibles en transportación, en hospedaje y hasta sistemas de créditos bien organizados, asimismo por estar fuertemente implicado en el fenómeno socioeconómico dela globalización.

Para México el turismo ha significado una importante fuente de divisas según datos de la OMT (2013) a nivel mundial, el país ocupó el $13^{\circ}$ sitio en captación de turistas internacionales y el lugar 23 en captación de divisas. Por otra parte el informe publicado por la SEMARNAT (2007), señaló que el 45\% de la actividad turística está emplazada en zonas costeras.

El modelo de sol y playa es predomínate en los principales destinos turísticos, no obstante las nuevas tendencias que nivel mundial están promoviéndose. Dicho modelo se ha caracterizado por su afluencia masiva y que al paso del tiempo ha sido causa de la degradación ambiental de muchos ecosistemas costeros, dada la discrecionalidad en el cumplimiento de leyes y normas para su cuidado y conservación, situación que también sobrelleva el área estudiada.

Desde los primeros emprendimientos turísticos al suroeste de Nayarit y hasta la fecha, se ha ejercido un claro dominio sobre el litoral transformándolo en un importante recurso económico principalmente para la industria del turismo. Los municipios mayormente implicados como el caso de Compostela, en su zona conurbada a las playas de Rincón de Guayabitos, las actividades económicas giran en torno al turismo; sin embargo, la presión turística-recreativa que se genera sobre estos espacios ha derivado en impactos ambientales de difícil restauración. 


\section{Los destinos turísticos en zonas costeras}

Para distintos organismos nacionales e internacionales las zonas costeras son consideradas como un medio ambiente natural de incalculable valor (FIG, 2008; ProCostas, 2008; SEMARNAT, 2011; PNUMA, 2012), pues contienen los ecosistemas de mayor diversidad y productividad del planeta, constituyen un todo integrado que es un componente esencial del sistema mundial de sustentación de la vida y un valioso recurso que ofrece posibilidades para un desarrollo sostenible, ya que producen la mayor cantidad de recursos pesqueros y sostienen una significativa parte de la actividad portuaria y de transporte, la agricultura, la industria y el turismo mundial.

A la zona costera se le conoce comúnmente como la línea de costa que representa el límite entre los ambientes marinos y terrestres, el lugar donde la tierra se encuentra con el mar, para los fines del estudio se consideraron los siguientes referentes que son determinantes para programas de gestión en ese tipo de espacios costeros.

La International Federation of Surveyors (FIG) en el documento Declaración de Costa Rica. Gestión de zonas costeras a favor de los pobres, señaló:

“... el criterio sobre qué constituye un área costera, tanto en dirección a la tierra como al mar, cambia según la jurisdicción. En algunos países europeos se considera que la zona costera misma se extiende en dirección al mar hasta el límite territorial, mientras que otros consideran el borde de la plataforma continental, cerca del contorno de $200 \mathrm{~m}$ de profundidad, como el límite de esta zona. En términos amplios, una zona costera se entiende como una extensión espacial definida que comprende la tierra (incluyendo el terreno sumergido), el mar y la interrelación tierra-mar, donde cada entidad, dentro de esta extensión espacial definida, ejerce una fuerte influencia sobre las otras, en términos de ecología y de utilización" (FIG, 2008, p.7).

En México, la Secretaría del Medio Ambiente y Recursos Naturales (SEMARNAT), en un concepto amplio define la zona costera como:

"El espacio geográfico de interacción mutua entre el medio marino, 
el medio terrestre y la atmósfera, comprendido por: a) una porción continental definida por 263 municipios costeros; 150 con frente de playa y 113 municipios interiores adyacentes a estos con influencia costera alta y media, b) una porción marina definida a partir de la plataforma continental delimitada por la isobata de los $20 \mathrm{~m}$. y, c) una porción insular representada por las islas nacionales" (SEMARNAT, 2011, p.8).

De manera específica define la playa como:

"Unidad geomorfológica conformada por la acumulación de sedimentos no consolidados de distintos tipos y cuyos límites se establecerán, considerando límite inferior y límite superior.

- Límite inferior: Se establecerá a una distancia de 200 m medidos a partir del límite hacia el mar de la zona federal marítimo terrestre. En caso de no existir dicho límite, la medición se considerará perpendicularmente desde la proyección vertical de la línea de pleamar hacia el mar.

- Límite superior: Se establecerá por la presencia de algún tipo de construcciones cimentadas, presencia de vegetación permanente, presencia del segundo cordón de dunas o presencia de cantiles costeros". (CONAGUA, 2011, p.7).

En cuanto a los usos costeros Justafré (2009), explica que puede entenderse al conjunto de actividades que tienen lugar en la zona costera y las que utilizan y/o explotan los recursos existentes en dicha zona, de acuerdo con los usos costeros pueden agruparse en cinco categorías principales:

Primera: el uso residencial consiste básicamente en la urbanización de la zona costera para el asentamiento de la población;

Segunda: aprovechamiento de los recursos vivos (renovables) relacionadas con la pesca en sus diferentes vertientes y a la explotación de recursos no vivos (no renovables) se refiere principalmente a actividades extractivas de petróleo y generación de electricidad;

Tercera: la utilización de la zona costera para la construcción de infraestructuras está relacionada principalmente con el transporte marítimo, destacando en este caso la 
construcción de instalaciones portuarias;

Cuarta: corresponde al uso turístico y recreativo, se relaciona básicamente a la explotación de esta zona para actividades de placer y ocio;

Quinta: las actividades de conservación y protección ambiental que se refieren a una regulación estricta (en muchos casos prohibición) de los usos anteriores para la preservación y/o mejora de los valores ambientales de la zona costera.

Se reconoce por el Programa de las Naciones Unidas para el Medio Ambiente (PNUMA, 2012) la característica común que puede encontrarse en cualquier costa del mundo, es la atracción que ésta ejerce sobre la población, de tal forma que, en términos generales, es la zona más intensamente usada tanto para el asentamiento de la población como para la explotación de los recursos.

Se estima que más de la mitad de la población mundial vive dentro de una franja de $100 \mathrm{~km}$ de costa, y se prevé que para el año 2025, el 75\% de la población mundial podría habitar en las zonas costeras, conformando megalópolis con problemas de marginación y pobreza, así como los consecuentes impactos ambientales derivados del abasto para las mismas y la generación de enormes volúmenes de desechos, contaminación de acuíferos y deterioro generalizado (SEMARNAT, 2011).

La dinámica poblacional de las zonas costeras de México sigue las tendencias mundiales, que indican un desplazamiento de las poblaciones humanas hacia las zonas costeras. En el año 2005 la población de los estados costeros fue de 47, 344,698 habitantes, 2.7 millones más que en el año 2000. Se espera que para el año 2030 aumenten a 55 millones (CONAPO, 2006).

De las 32 entidades federativas del país, 17 tienen frente litoral; existen 263 municipios costeros, de los cuales como ya vimos 150 cuentan con frente de mar y 113 municipios con influencia costera. La superficie de la zona económica exclusiva $(2,715,012 \mathrm{Km} 2)$ del país, incluida la del mar territorial $(231,813 \mathrm{Km} 2)$, es más extensa que la superficie continental de México $(1,959,248 \mathrm{Km} 2)$, y constituye un espacio del territorio nacional que debe ser gestionado de manera sustentable, para beneficio de la nación (INEGI, 2010., SEMARNAT, 2011). 


\section{Imagen 1. Zona Económica Exclusiva de México y sus alrededores}

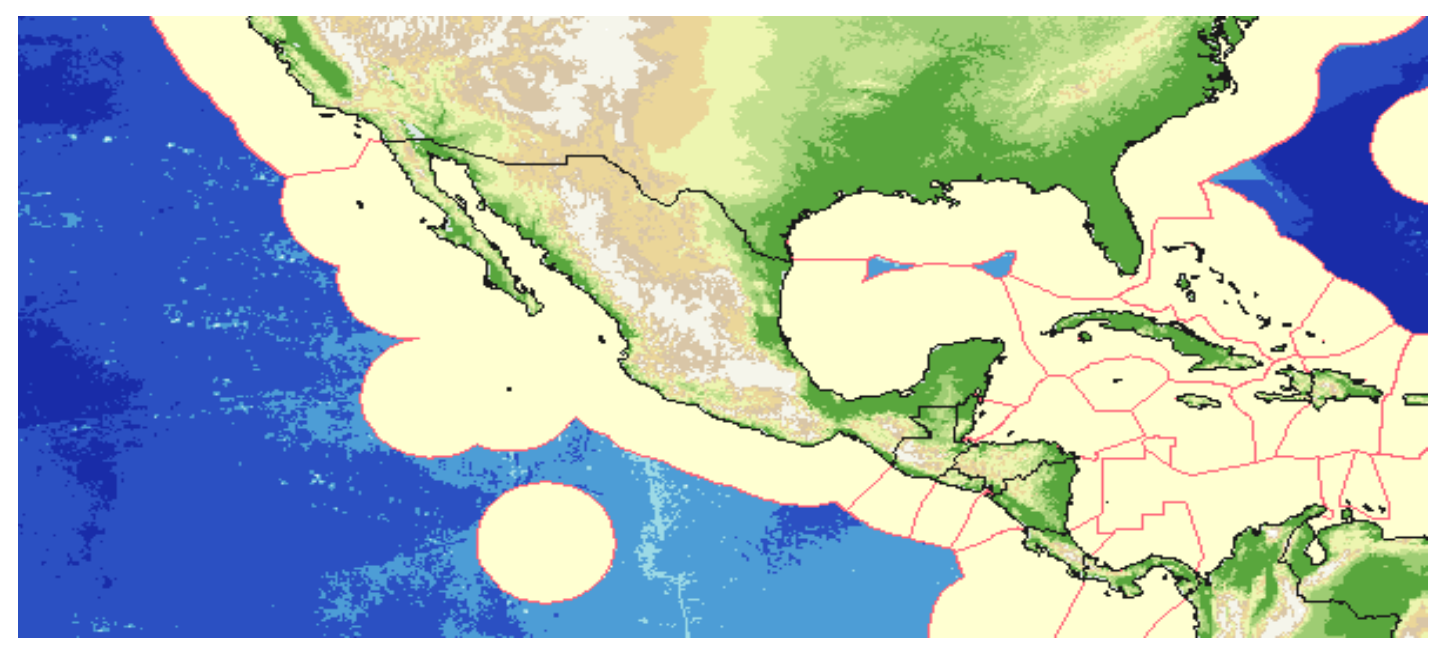

Fuente: Flanders Marine Institute. VLIZ (2008). Maritime Boundaries Geodatabase. Obtenido de SEMARNAT, 2011.

Por los usos y funciones de los mares y zonas costeras, en México adquieren una importancia estratégica y son parte fundamental tanto desde el punto de vista del desarrollo económico como de la seguridad nacional, la soberanía y el desarrollo sustentable al albergar una alta diversidad de actividades económicas (SEMARNAT, 2007, 2011).

Por lo que corresponde al uso turístico y recreativo, el informe de la SEMARNAT (2007), registró que en México el $45 \%$ de la actividad turística está emplazada en la costa, y a nivel mundial, México ocupa el $13^{\circ}$ sitio en captación de turistas internacionales y el lugar 23 en captación de divisas de acuerdo al último barómetro del turismo de la OMT (2013).

Al territorio nayarita le corresponden $304 \mathrm{kms}$ de costa, de los cuales 164 corresponden a la costa norte y 140 a la costa sur. Dichos espacios litorales, constituyen hoy un importante recurso turístico y económico, tan es así, que en los dos últimos Planes Estatales de Desarrollo (PED) y los respectivos Programas Regionales postulan esta actividad como eje estratégico de desarrollo y el que mayor potencialidades muestra para sacar del estancamiento al estado. Conforme al estudio de Identificación de Oportunidades Estratégicas para el Desarrollo del Estado de Nayarit 2009 del Tecnológico de Monterrey, incluido en el actual Plan Estatal de Desarrollo (PED) 2011-2017 el desempeño económico de Nayarit ha estado fomentado primordialmente por la inversión en el sector energético y turístico (Gobierno del Estado de Nayarit, 2011). 
Los beneficios económicos asociados a la actividad turística son innegables, pero debemos tener muy presente los efectos negativos que conlleva sobre el medio marino y costero los cuales ponen en riesgo la viabilidad de la propia actividad. El desarrollo acelerado de esta actividad económica, ha inducido un crecimiento desordenado en la zona costera y zonas urbanas de la costa, con los consecuentes conflictos ambientales derivados de la competencia por el espacio y el uso de los recursos, la generación de residuos y contaminantes, descarga de aguas residuales sin el debido tratamiento y peor aún, en muchos casos sin ningún tipo de tratamiento entre otros (Díaz, 2006; ProCostas, 2008).

En pertinente recordar aquí, que desde finales de la década de los ochentas y hasta la fecha, en las cumbres mundiales celebradas bajo los auspicios de la Organización de Naciones Unidas (ONU), se han establecidos consensos en torno a la procuración del desarrollo sostenible, que entre otros destaca la Agenda 21 para su implementación a todas las actividades productivas de la economía mundial con implicancia en lo ambiental y social. En ese contexto, los diversos organismos internacionales y gobiernos nacionales también han definido su propia Agenda 21 según ámbitos de competencia.

Por su parte, en la Conferencia Mundial de Turismo Sostenible (La Carta del Turismo Sostenible. Islas Canarias, España, 1995), tres organizaciones globales líderes del sector, la Organización Mundial del Turismo (OMT), el Consejo Mundial de Viajes y Turismo (WWTC) y el Consejo de la Tierra, unieron esfuerzos para realizar un estudio sobre la agenda 21 y formularon la "Agenda 21 para la Industria de Viajes y Turismo", cuyo programa de acción orienta y apoya a los organismos gubernamentales responsables del turismo, a las administraciones turísticas nacionales y a los representantes comerciales y a las empresas, impulsándolos a comprometer su potencial hacia el logro del desarrollo sustentable local y nacional (Verdugo y García, 2007).

En consecución de tales esfuerzos, la Organización Mundial del Turismo (OMT) declaró en 1998, que el propósito del turismo sostenible consiste en liderar el manejo de los recursos de manera que las necesidades económicas, sociales y estéticas se puedan alcanzar, mientras se mantiene la integridad cultural, los procesos esenciales ecológicos, la diversidad biológica y el soporte de los sistemas de vida. Así mismo, lo considera una práctica al ser aplicada en todas las formas de turismo y en todos los tipos de destino turístico.

En el ámbito de la investigación turística, la competitividad de los destinos turísticos se puede 
definir como "la capacidad del destino para crear e integrar productos con valor añadido que sostienen sus recursos, al tiempo que mantienen su posición en el mercado respecto a sus competidores" (Hassan, 2000, p.239).

También se puede definir, de acuerdo a Ritchie y Crouch (2003), como la capacidad de un país para crear valor añadido e incrementar, de esta forma, el bienestar nacional, la gestión de ventajas y procesos, atractivos, agresividad y proximidad, integrando las relaciones entre los mismos en un modelo económico y social.

En base a la constante evolución de las teorías en la esfera del turismo, el concepto de competitividad ha evolucionado también desde el enfoque tradicional basado fundamentalmente en la llamada teoría de la ventaja comparativa, teoría que defiende que un destino es más competitivo cuantos más recursos directos e indirectos disponga, hacia un enfoque basado en la teoría de la ventaja competitiva. Esta teoría establece que un destino es más competitivo cuanto mayor sea la capacidad de los gestores del mismo para agregar valor a un producto o servicio igualmente comercializado en otros destinos competidores (Orta, 2005).

De acuerdo con Orta, no se trata de una exclusión de las ventajas comparativas. Ya que en el caso de la actividad turística los factores de la competitividad residen en ambas. Sin embargo, y sin desestimar la importancia de contar con recursos turísticos de primer nivel, si se les agrega valor, puede marcar la diferencia entre destinos exitosos o no. Esta añadidura de valor, se encamina, por un lado, a la mejora de la eficiencia en el consumo de los recursos (mejora de la productividad) y por otro, a la generación y distribución de la riqueza en el destino. Desafortunadamente actualmente en muchos destinos turísticos de sol y playa sean de grandes o medianas dimensiones, algunos de los problemas ambientales asociados a las actividades del sector continúan presentándose, pues dadas las características climáticas de los litorales y la gran cantidad de playas atractivas que contienen, el turismo es el uso más importante para los desarrolladores en las costas, situación que permea en Rincón de Guayabitos.

La Gestión Integral de Zonas Costeras ha sido ampliamente investigada y documentada en publicaciones a nivel mundial, y podemos encontrar diversos términos que han sido utilizados para describir el Proceso de Manejo de la Actividad Humana en la Zona Costera. 
En México las autoridades responsables en la materia utilizan el termino Manejo Sustentable de Mares y Costas (MSMC).

El MSMC puede definirse como un proceso continuo y dinámico de participación y gestión que articula Estado y sociedad para regular el ordenamiento territorial y el uso de la costa, en pos de la calidad de vida de las comunidades actuales y futuras. Considera la armonización entre la conservación de los ecosistemas, los procesos ambientales y el desarrollo de la sociedad. Tal proceso debe desarrollarse mediante objetivos precisos, pautados en el tiempo e incluir planes de control y monitoreo. En tal sentido, dicho proceso debe constituir un compromiso político que exige estrategias sustentables con recursos suficientes y necesarios para su eficiente desarrollo (ProCostas, 2008).

Ante la necesidad de abocarse a la mejora de la calidad ambiental y turística de la prestación de servicios en playas, desde el año 2003 diversas instancias gubernamentales unieron esfuerzos para la conformación del Programa Playas Limpias (PROPLAYAS), en el que participan la Secretaría del Medio Ambiente y Recursos Naturales (SEMARNAT), Comisión Federal para la Protección contra Riesgos Sanitarios (COFEPRIS), Secretaría de MarinaArmada de México (SEMAR), Secretaría de Turismo (SECTUR), Procuraduría Federal de Protección al Ambiente (PROFEPA), Comisión Nacional del Agua (CONAGUA), Gobiernos Estatales y Municipales para la elaboración de un conjunto de directrices que promovieran la gestión de calidad y el cuidado ambiental en áreas costeras y litorales con el objetivo de lograr una mejor calidad ambiental de las playas mexicanas.

En Nayarit desde el año 2003 se conformó el comité y ha sido uno de los que más playas han logrado certificar, desafortunadamente se han concentrado en el municipio de Bahía de Banderas.

La SEMARNAT en su última actualización del año 2016 puntualiza que la Norma Mexicana NMX-AA-120-SCFI-2016 establece los requisitos y especificaciones de sustentabilidad para playas en dos modalidades: 1) Uso recreativo. 2) Prioritaria para la conservación. De manera específica incluye medidas ambientales para la protección al ambiente, en las playas turísticas de México, en materia de calidad de agua, residuos sólidos, infraestructura costera, biodiversidad, seguridad y servicios, educación ambiental y contaminación por ruido.

Es importante mencionar que el PROPLAYAS ha quedado ligado al Acuerdo Nacional por el Turismo -signado en febrero de 2011- y cuyo objetivo es "Proteger la salud de los usuarios, 
mejorar la calidad ambiental de las playas nacionales y elevar los niveles de competitividad de los destinos turísticos, mediante la realización de acciones coordinadas de los tres órdenes de gobierno y los sectores privado, social y académico" (CONAGUA, 2012, p.3).

\section{Métodos e instrumentos}

Se retoman aquí parte de los resultados del estudio denominado "Evaluación de las características de sustentabilidad y competitividad para el destino turístico de sol y playa Rincón de Guayabitos, Nayarit" investigación realizada por los autores del presente capítulo. Se realizó una evaluación de las condiciones persistentes en Rincón de Guayabitos y su conurbación con la Peñita de Jaltemba, municipio de Compostela, Nayarit. Se definieron como categorías fundamentales la Sustentabilidad y la Competitividad y se determinó para su análisis la variable de Condiciones del Destino turístico de sol y playa, que comprende los indicadores de Factores de Soporte, Planta y Servicios Turísticos, Recursos y Atractivos Turísticos, y la Gestión; dichos indicadores de calidad permitieron evaluar, no sólo las características intrínsecas y estéticas del recurso, sino también la gestión del recurso, equipamiento, actividades, seguridad e información medioambiental.

Para el análisis como destino turístico de sol y playa, se retomaron las aportaciones de (Jiménez y Aquino, 2012) "Modelo de Análisis de Competitividad de Destinos Turísticos", así como de la aportación de Popoca y Espejel (s/f) "Propuesta de una metodología para evaluar playas recreativas con destino turístico. En ese marco teórico-metodológico se determinaron las siguientes etapas de trabajo:

\section{Condiciones del Destino}

Se subdividió el área de estudio en las dos zonas siguientes:

a) "Zona del Litoral", que corresponde a la Playa Guayabitos y que de acuerdo a la SEMARNAT se divide en las secciones I y II.

Para el registro y análisis de cada uno de los factores, se utilizó la Ficha descriptiva de la calidad de playa, la cual integra 45 indicadores, desagregados en 15 de infraestructura y servicios, 21 ecológicos y 9 de limpieza, que en conjunto expresan las condiciones de calidad 
de la playa Guayabitos para la recreación.

En la propuesta de Popoca y Espejel (s/f), se combinan los métodos de valoración de Micallef y Williams (2004) y de Cendrero y Fischer (1997). Es decir, se obtiene el promedio de todas las características evaluadas y se divide entre cinco (el valor más alto en esta escala de evaluación). De esta forma, los datos quedan en un intervalo de un mínimo de 0.2 (con una aptitud recreativa muy mala) hasta un máximo de 1 (con una aptitud recreativa muy buena). Para comparar los valores obtenidos establecieron tres intervalos (alto, medio y bajo) que se muestran en la tabla 1:

Tabla 1. Valores de los intervalos de calidad de la playa

\begin{tabular}{|c|c|}
\hline $\begin{array}{c}\text { Calificativo de } \\
\text { Calidad }\end{array}$ & Intervalos \\
\hline Bajo & $0.20-0.46$ \\
\hline Medio & $0.47-0.73$ \\
\hline Alto & $0.74-1.00$ \\
\hline
\end{tabular}

Fuente: Popoca y Espejel s.f.

b) "Zona Urbana", ésta comprende básicamente la avenida Sol Nuevo, los andadores y un par de plazas.

Se utilizó una "Guía de observación del área urbana de Rincón de Guayabitos" con el propósito de clarificar la situación competitiva del sitio, que permitan formular estrategias específicas para su mejora.

Con mayor profundidad se analizó la gestión de la playa, la cual se considera una de las mayores ventajas comparativas de este destino turístico y que constituyó el elemento de interés en este objeto de estudio.

Para tal caso se utilizó el instrumento "Guía de entrevista a funcionarios públicos" relacionados con el turismo, El criterio de selección fue incluir en la entrevista a funcionarios de las dependencias gubernamentales con mayor responsabilidad de evitar o de generar acciones de la disminución de daños que en todos los ámbitos causa o pueda causar la actividad turística en el destino. También se optó, por la elección de Organismos No Gubernamentales $(\mathrm{ONG})$ que accionan a favor de la temática del caso en cuestión. 
Se consideró además que la socialización de los resultados del estudio a los involucrados en la entrevista, pudiera ser un movilizador para nuevas acciones tendientes a robustecer la sustentabilidad y competitividad de Rincón de Guayabitos y su conurbación con la Peñita de Jaltemba como destino turístico de sol y playa.

\section{Resultados y Discusión Aspectos generales del área estudiada}

Rincón de Guayabitos es un destino turístico perteneciente al municipio de Compostela y a su vez dicho municipio junto con el de Bahía de Banderas conforman la "Región Costa Sur" del Estado de Nayarit, la cual desde el punto de vista fisiográfico, se asienta en la provincia de la Sierra Madre del Sur, subprovincia de las sierras de la costa de Jalisco y Colima, lo que da por resultado el paisaje insólito de playas colindantes con cerros y acantilados, que en el caso de Nayarit significa mayor diversidad de tipo de playas, con respecto a los otros estados.

Rincón de Guayabitos es un pequeño poblado costero, ubicado a $98 \mathrm{~km}$ al suroeste de Tepic, la capital del Estado. Por sus condiciones naturales, Guayabitos es hoy una zona turística que constituye una actividad de vital importancia para la economía del municipio y para la entidad en general.

Imagen 2. Localización de Rincón de Guayabitos, Nayarit

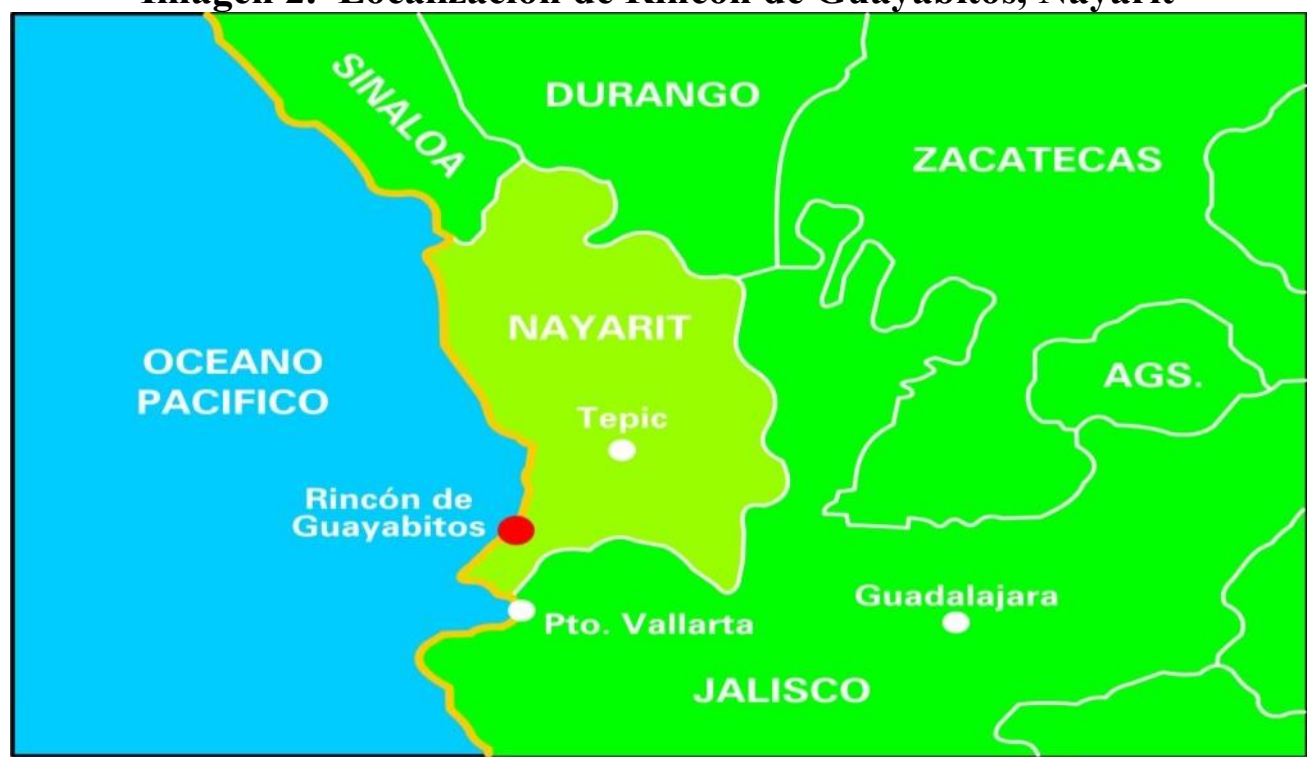

Fuente: http://www.bungalowsesmeralda.com/Guayabitos.jpg 
Este destino turístico tiene sus orígenes en la década de los setenta como lo explica Fonseca (2010), cuando la Costa Sur de Nayarit es incorporada a las regiones aptas para el fomento del turismo en México. Se inicia mediante la expropiación de tierras ejidales por un total de 4,136 hectáreas a lo largo de la planicie costera que en ese tiempo correspondían al municipio de Compostela, se le constituyó un patrimonio territorial al Fideicomiso Bahía de Banderas que se destinaría a la implantación del $<<$ Programa de Desarrollo Turístico y Habitacional $>>$ (PDTH) que se conectaría a Puerto Vallarta, Jalisco, dando lugar a la visión de configurar a mediano plazo un corredor turístico en esta franja costera.

En ese contexto, para la zona de Rincón de Guayabitos se definió una planeación integral, que incluyera áreas residenciales, hoteleras, comerciales y una urbanización de primera calidad, así al correr de los años fue conformándose como el espacio turístico ahora visitado por nacionales y extranjeros.

Actualmente se cuenta con un fraccionamiento de segunda vivienda de baja densidad poblacional, 108 hoteles y/o bungalows que van una a cinco estrellas y que en conjunto aportan un total de 2,741 cuartos disponibles; cabe destacar que dichos establecimientos de hospedaje son de mediana altura (no mayores de cuatro niveles) acuerdo tomado y reglamentado por los desarrolladores desde su emprendimiento a fin de no alterar el paisaje local. Se tienen además, restaurantes de especialidades, centros nocturnos, tiendas de autoconsumo, trailers-park y todos los servicios que se requieren para el desarrollo de la actividad turística.

Rincón de Guayabitos está en conurbación con La Peñita de Jaltemba, pueblo de mayor antigüedad el cual concentra la mayor parte de la población que conforma la fuerza laboral de los servicios turísticos de la zona. Cuenta con pequeños hoteles y bungalows, casas de renta, bares y discotecas, diversos supermercados, restaurantes y una amplia variedad de comercios; por lo que en temporada baja su vida nocturna es más activa que la de Rincón de Guayabitos.

Con relación a la demanda turística, este destino turístico ha contado con una importante preferencia de turismo extranjero principalmente de origen canadiense con estancias prolongadas en la temporada invernal. El resto del año es frecuentado periódicamente por turistas que vienen del centro de la república mexicana que viajan en su propio vehículo y 
una cantidad mayor viaja en autobuses en paquetes preferenciales para excursionistas.

Dentro de la longitud costera denominada Bahía de Jaltemba se localizan diversas playas: la del beso, frideras, frideritas y en algunas de ellas sólo puede accederse por mar como la playa del toro. Por su parte la Playa guayabitos se ha ganado el título de "la alberca al natural más grande del mundo" con extensión de 2 kilómetros de longitud por 30 metros de ancho; sus olas tranquilas y tibias todo el año son ideales para practicar deportes acuáticos como son: canotaje, remo, esquí, veleo y otros; cuenta además, con la Isla del Coral, rodeada de arena blanca y textura fina que dan la transparencia a sus aguas lo que permite admirar una gran diversidad de peces y coral blanco atractivos naturales que incitan la práctica del buceo y el esnorquel.

\section{Imagen 3. Panorámica de la Bahía Rincón de Guayabitos, Nayarit}

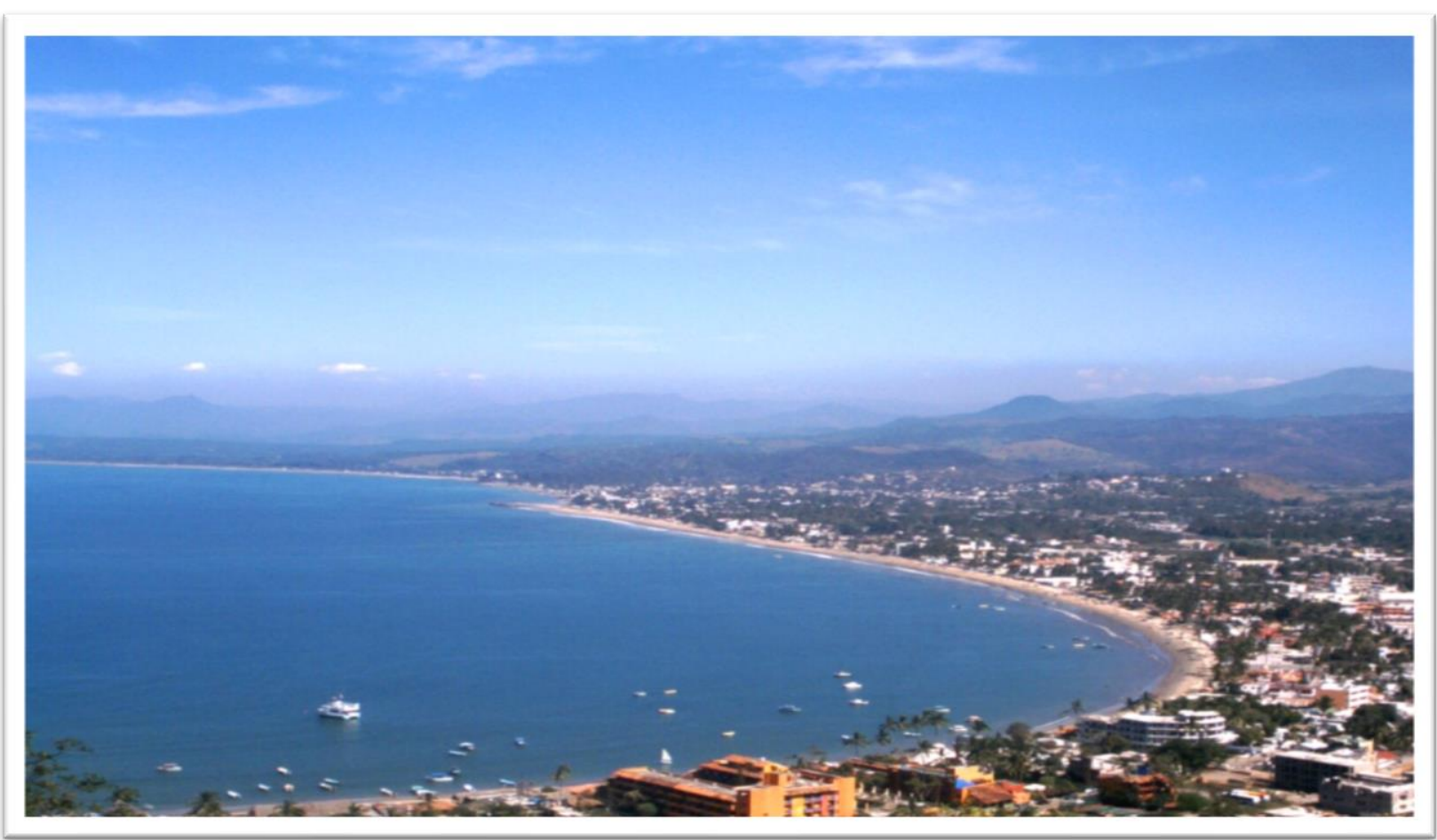

Fuente: Asociación de Hoteles y Moteles de Rincón de Guayabitos 


\section{Condiciones generales en playas}

Las playas de Rincón de Guayabitos, muestran una aptitud recreativa intermedia, destacan los buenos resultados de los indicadores de morfología y oceanografía, que tienen que ver con las características de oleaje, profundidad, etc. que la hacen apta para el disfrute y seguridad del baño, así como sus accesos, aunque el factor de estacionamientos influye para posicionarse en ese calificativo; pero también es muy notorio que el puntaje más bajo corresponde a la calidad del agua y emisión de ruidos, como se observa en la tabla 2 con los datos de valoraciones resultantes sobre la calidad de la playa en cuestión:

\section{i. Gestión actual en playas}

De los resultados derivados de las entrevistas a funcionarios relacionados con la gestión y desarrollo del destino, se expone el siguiente resumen:

Todos los entrevistados coincidieron que al menos en un mediano plazo la certificación de la playa no será posible, dada la situación crítica en que se encuentra el destino. Incidiendo factores tales como:

$>$ Falta de infraestructura urbana y de servicios,

$>$ Ambulantaje excesivo y fuera de control,

$>$ Leyes y reglamentos,

$>$ Ineficiencia oficial de los niveles de gobierno involucrados,

$>$ Desorden y anarquía de los prestadores de servicios,

$>$ Bajo nivel de conciencia de turistas y locales. 
Tabla 2. Resultados de la evaluación en playas Rincón de Guayabitos

\begin{tabular}{|c|c|c|c|}
\hline \multirow{3}{*}{ Indicador } & \multicolumn{3}{|c|}{ Calificativo de Calidad } \\
\hline & Bajo & Medio & Alto \\
\hline & $0.20-0.46$ & $0.47-0.73$ & $0.74-1.00$ \\
\hline $\begin{array}{c}\text { Infraestructura y } \\
\text { servicios }\end{array}$ & & 0.60 & \\
\hline Accesos & & 0.60 & \\
\hline Servicios Públicos & & 0.50 & \\
\hline Servicios Turísticos & & & 0.75 \\
\hline Infraestructura & & 0.55 & \\
\hline Ecológico & & & 0.83 \\
\hline Morfología & & & 0.86 \\
\hline Oceanográfico & & & 0.90 \\
\hline Biótico & & 0.72 & \\
\hline Limpieza & & 0.65 & \\
\hline Olores & & & 0.80 \\
\hline Basura & & & 0.76 \\
\hline Calidad del Agua & 0.30 & & \\
\hline Ruido & 0.40 & & \\
\hline
\end{tabular}

Fuente: Puentes, 2013.

\section{ii. Imagen: Zona urbana}

La Avenida Sol Nuevo. Rincón de Guayabitos cuenta únicamente con una avenida principal, tiene varios accesos de entrar y salir, pero los que están sobre la carretera federal 200 que es la vía de llegada son únicamente dos. Para efectos de este apartado se dividió la avenida en tres zonas: zona hotelera y comercial (ubicadas al sur y centro), cuenta con diversos servicios para el turista, se pueden encontrar restaurantes, supermercados o minisuper, farmacias, esteticas, discotecas, joyerias, tiendas de regalos y artesanías, tiendas de ropa y articulos para la playa, etc., así como también un área residencial (hacia el norte de este desarrollo) a continuación en la tabla 3 se resume por grupos los factores y resultados de la observación directa en esta parte del área en cuestión.

Tabla 3. Resultados de observación de la Avenida Sol Nuevo 


\begin{tabular}{|c|c|c|c|c|c|c|c|c|c|c|}
\hline \multirow[t]{2}{*}{ AVENIDA SOL NUEVO } & \multicolumn{5}{|c|}{ Zona Sur } & \multicolumn{5}{|c|}{ Zona Centro } \\
\hline & 5 & 4 & 3 & 2 & 1 & 5 & 4 & 3 & 2 & 1 \\
\hline LImpleza & \multicolumn{5}{|c|}{ Presenda - Ausen da } & \multicolumn{5}{|c|}{ Presenda - Ausencla } \\
\hline Basura & $x$ & & & & & & & & $\mathrm{x}$ & \\
\hline Cumulos de Basura & & $\mathrm{x}$ & & & & & & & & $\mathrm{x}$ \\
\hline Botes de basura & & $\mathrm{x}$ & & & & & & $\mathrm{x}$ & & \\
\hline Nivel de ruldo & & $x$ & & & & & $x$ & & & \\
\hline Olores desagradables & & $\mathrm{x}$ & & & & & & & $\mathrm{x}$ & \\
\hline \multicolumn{11}{|l|}{ E spac lo Flsico } \\
\hline E spados para estaclon ar & & & & & $x$ & & & & & $x$ \\
\hline Zonas pea ton ales (Ilbertad para camınar) & & & $x$ & & & & $\mathrm{x}$ & & & \\
\hline Trafico en las calles & & & $x$ & & & & & $\mathrm{x}$ & & \\
\hline Imagen urbana & \multicolumn{5}{|c|}{ Agradable - Desagradable } & \multicolumn{5}{|c|}{ Agradable - De sagradable } \\
\hline Ve getadion y are as verdes & & & & $\mathrm{x}$ & & & & $\mathrm{x}$ & & \\
\hline An und os y publld dad & & & & $\mathrm{x}$ & & & & $\mathrm{x}$ & & \\
\hline PIntas en muros & & & $\mathrm{x}$ & & & & & $\mathrm{x}$ & & \\
\hline E quipa mento U raano & \multicolumn{5}{|c|}{ Presenda - Ausen da } & \multicolumn{5}{|c|}{ P resencla - Ausencla } \\
\hline Aumbrado pub ll $\infty$ & & $\mathrm{x}$ & & & & & $\mathrm{x}$ & & & \\
\hline Tele tonos & & $\mathrm{x}$ & & & & & $x$ & & & \\
\hline Cajeros Automaticos & & & & $\mathrm{x}$ & & & & & $x$ & \\
\hline Cuemos polldacos & & & & $x$ & & & & $x$ & & \\
\hline
\end{tabular}

Fuente: Trabajo de campo, 2013.

En la avenida se presentan diferencias muy marcadas mientras que en la zona centro se aprecia una imagen agradable y con cierta armonía, en las otras zonas se presentan invasión de la vía pública por ambulantaje y puestos semifijos, también acumulación de basura sobre el camellón central aspectos negativos que afectan no solo en la imagen del destino, sino que además pone en riesgo la seguridad y movilidad tanto de peatones como de vehículos.

Plazas y Andadores Públicos. Por sus características se puede considerar que son el potencial turístico de estas zonas ya que sirven parque o zona de descanso; en las cuales se pueden realizar actividades recreativas. Pero la escasez de equipamiento y acondicionamiento es una de las razones por las cuales usuarios potenciales no las visitan. Un aspecto muy sensible del crecimiento urbano es el requerimiento de servicios públicos relacionados con el tratamiento de aguas residuales y la red de drenaje pluvial y sanitario, sobre todo en lo que al cuidado del medio ambiente se refiere, tanto por razones de salud pública, como por el saneamiento requerido respecto al cuidado de la calidad del agua en las playas para impulsar el desarrollo turístico sostenible. 
Son de los problemas más graves y añejos que enfrenta Rincón de Guayabitos (en adelante RG). Anteriormente, se asociaba contaminación de la bahía, como consecuencia de la inoperancia de la laguna de oxidación de la Peñita de Jaltemba.

Se reemplazó el anterior sistema por una planta de tratamiento de aguas residuales, sin embargo la capacidad de operación también ha quedado desfasada desde hace varios años y entre otros factores ha originado que el estero que divide a RG y La Peñita de Jaltemba se encuentre contaminado por residuos sólidos y descargas de aguas residuales que bajan al mar en temporadas de lluvias agudizando el problema de su contaminación, que eventualmente se ha declarado a la zona en riesgo sanitario, pero se trata encubrir la situación por el temor de que se difunda una mala imagen que repercuta en la afluencia de visitantes.

Las deficiencias encontradas en los hoteles en cuanto al rubro ambiental; Agua, fueron las siguientes:

- En el $20 \%$ de los hoteles, el agua proviene del lavado de las albercas se descarga directamente sobre la playa y fluye hasta el mar.

- El $100 \%$ de las empresas descargan sus aguas residuales sanitarias al sistema de alcantarillado municipal, no se tienen análisis de las mismas y no cuentan con medidor volumétrico, por lo que se desconoce la calidad y cantidad de agua.

- El $100 \%$ desconoce los volúmenes de agua de suministro, ya que no tienen instalado un medidor de gasto de su abastecimiento de agua potable.

- El $100 \%$ de las empresas no han implementado programas de ahorro en el consumo de agua y electricidad, en este sentido el 90\% tienen instaladas "cebollas" de alto consumo eléctrico, para calentar el agua.

Leyes y Reglamentos. En la opinión generalizada, las autoridades están completamente rebasadas, por una parte la ausencia de ordenamiento y aplicación de leyes y reglamentos, aunado a la complacencia, discrecionalidad, corrupción e impunidad de las autoridades ha propiciado falta de respeto y credibilidad de las mismas, llevando a un estado de anarquía, vandalismo y mafias, donde los diversos actores accionan de acuerdo a sus intereses. Por otra parte la obsolescencia de las leyes y la falta de oficinas de la PROFEPA dentro de la zona afectan en la capacidad de respuesta e inhibe la denuncia. 


\section{Imagen 4. Turismo masivo de sol y playa}

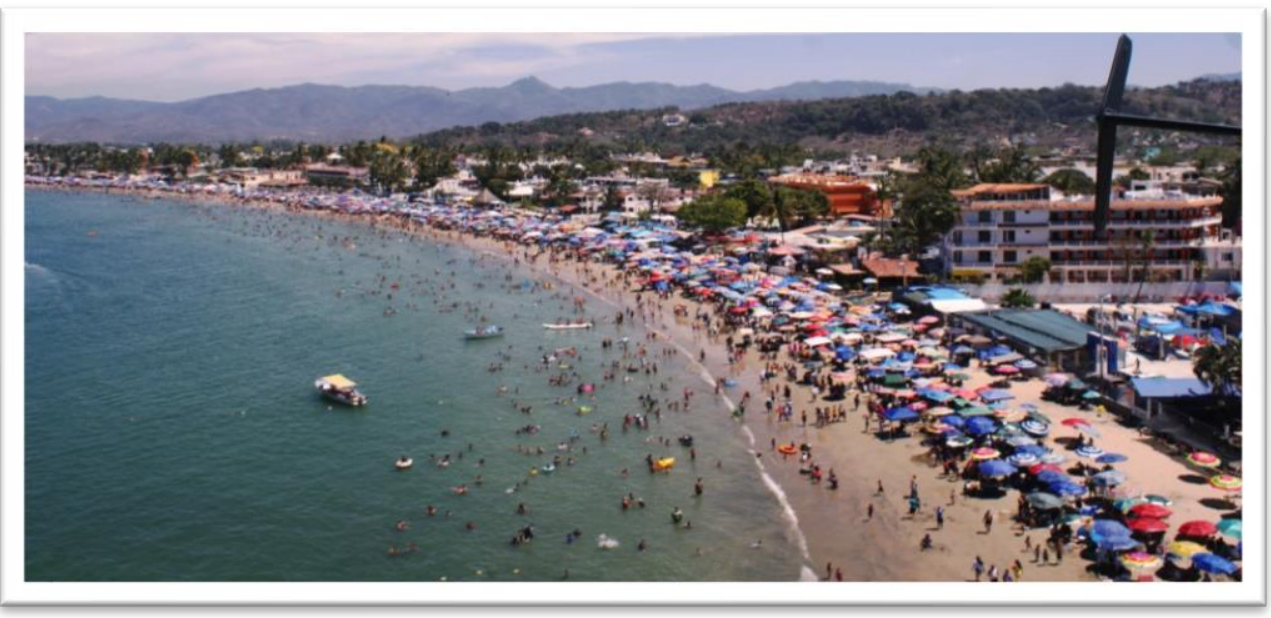

Fuente: Asociación de Hoteles y Moteles de Rincón de Guayabitos

Nivel de Participación Gubernamental. En este rubro hay coincidencia entre los entrevistados que es necesaria una mayor coordinación y organización de las dependencias en la atención de los asuntos de su competencia, se advierte una falta general de acción sobre cada una de las abundantes recomendaciones que se formulan en los programas de desarrollo sustentable para los destinos turísticos, por otra parte nos topamos con la carencia y la dificultad para disponer de los recursos humanos y financieros suficientes y peor aún, con la falta de voluntad política para intentar una disminución de la problemática que origina esta actividad en la zona. 
Imagen 4. Deficiente ordenamiento en zona de playa

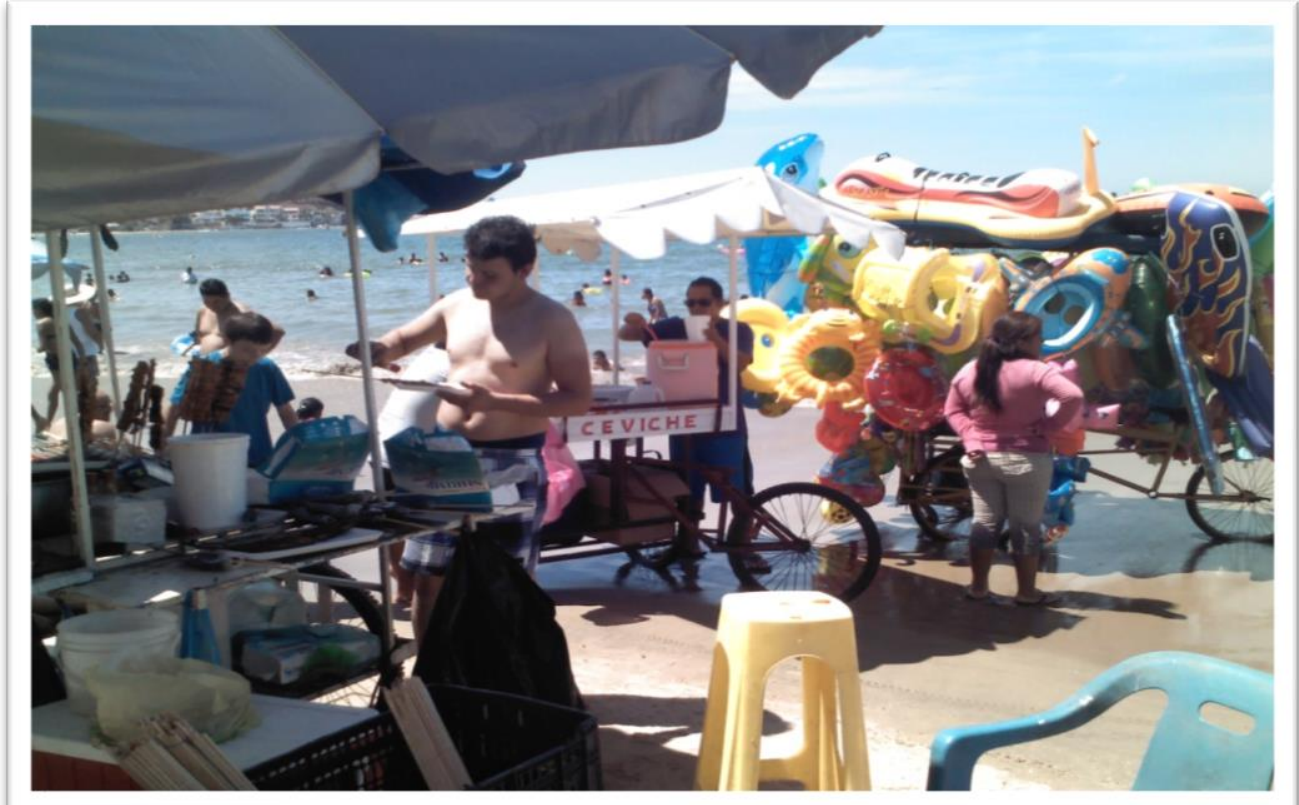

Fuente: Puentes, 2013.

En cuanto a la participación y colaboración del sector empresarial, de servicios y sociedad civil, se identificó Interés por Mantener Limpias las Zonas Turísticas, a pesar de ser un poco desorganizados, los esfuerzos por parte empresas del ramo turístico y grupos de ciudadanos en mantener limpias las playas, queda claro que estas personas físicas y morales tienen una conciencia y una genuina preocupación ecológica y muchos de estos esfuerzos se llevan a cabo en forma independiente, a través de campañas de limpieza, -lo cual quedo de manifiesto al realizar el recorrido por la playa, se pudo constatar los buenos resultados de estas accionesy a las labores de limpieza la Asociación de Hoteles, adquirieron una maquina "limpiaplayas".

\section{Socialización de resultados y estrategia de mitigación a puntos críticos}

Una vez concluida la "Evaluación de las características de sustentabilidad y competitividad para el destino turístico de sol y playa Rincón de Guayabitos, Nayarit" se llevó a cabo la socialización de los resultados obtenidos. Se dirigió preponderantemente a los participantes 
en la entrevista realizada durante el desarrollo del estudio, se explicaron los aspectos que han incidido en las condiciones positivas y negativas para el impulso de la sustentabilidad y la competitividad de éste destino turístico de sol y playa, mismos ya consignados en páginas anteriores.

Derivado del reporte de la evaluación y con el firme propósito mejorar su entorno los actores sociales de RG han tomado medidas de mitigación de los puntos críticos, a la fecha se verificaron las siguientes:

$\checkmark$ Remodelación de la Plaza pública, se le construyó u quiosco, un escenario y maceteras

$\checkmark$ Se adquirió máquina "limpia playas" de mayor tamaño

$\checkmark$ Se dotó de tres camiones nuevos para la recolección de basura

$\checkmark$ Remodelación a los andadores de acceso a la playa incluidos baños públicos (en construcción)

$\checkmark$ Se establecieron los compromisos de coordinación de limpieza y mantenimiento permanente para las diversas áreas públicas.

Las inversiones en equipo, obras de remodelación y tareas ordenadas han favorecido en mucho no sólo la imagen urbana sino también la calidad ambiental de Rincón de Guayabitos. Desafortunadamente sigue pendiente de resolver el punto más crítico que es el sistema operador de las aguas residuales, ya que al parecer ni las obras de rehabilitación a la planta de tratamiento de aguas residuales, así como la reparación y ampliación de la red de drenaje y alcantarillado realizadas aproximadamente tres años han sido suficientes para corregir la problemática de contaminación. En opinión tanto de empresarios como de la sociedad en general de RG, en ese sistema ha habido deficientes manejos, corrupción en su administración y la falta de mantenimiento, el cual a la fecha opera a un 50\% de eficiencia. No obstante perseveran en la gestión ante las autoridades del ramo para que se resuelva de manera integral. 


\section{Conclusiones}

El destino de sol y playa Rincón de Guayabitos presenta un satisfactorio conjunto de recursos naturales y atractivos turísticos. Los resultados revelaron que tanto de parte empresarios y sociedad local en general existe compromiso y buena disposición para lograr el mejoramiento ambiental de Rincón de Guayabitos, su mayor gestión se han concentrado en cumplir con las normas básicas de limpieza e instalación de ciertos servicios destinados al ocio y recreación y ya lograron obtener el estatus de playa limpia, que es el recurso y atractivo turístico más importante de este destino turístico.

Sin embargo, se requiere de mayor esfuerzo de gestión, frente a las autoridades especialmente sobre el tema del tratamiento de aguas residuales. Debido a lo cual no ha sido posible alcanzar la certificación de la playa, con base a los indicadores de la calidad de agua para uso recreativo en centros turísticos emitidos por la Comisión Federal para la Protección contra Riesgos Sanitarios (COFEPRIS), referentes al nivel bacteriológico en el agua del mar.

Se identificaron vacíos de coordinación entre las autoridades locales y estatales, involucradas con sector turismo: así como de ellas con los empresarios y sociedad local para resolver de fondo la problemática de ese punto crítico debido a deficiencias en el tratamiento de aguas residuales y que finalmente contaminan la bahía de Jaltemba.

Por lo anterior y a efecto de alcanzar parámetros satisfactorios de sustentabilidad y competitividad para el destino turístico de sol y playa Rincón de Guayabitos, es necesaria la atención inmediata de los factores que limitan su desarrollo, debido a que se postula, que es importante un cambio en la percepción y valoración de los recursos naturales, se reconoce que se trata de un proceso lento y de largo plazo.

Se recomienda, dar paso a la gestión integral de todos los actores sociales implicados en este destino turístico, de frente al reto de asegurar la conservación de sus recursos base, al mismo tiempo que productivamente sean innovadores en servicios de ocio y recreación a efecto de posicionarse entre los mejores estándares de calidad mundial. 


\section{Referencias bibliográficas:}

Comisión Nacional del Agua (CONAGUA). (2012). VIII Encuentro Nacional Playas Limpias. Disponible en: www.conagua.org.mx

FIG.(2008). Declaración de Costa Rica - Gestión de zonas costeras a favor de los pobres. (2008). Copenhague Dinamarca: International Federation of Surveyors. Disponible en:

https://www.fig.net/resources/publications/figpub/pub43_span/figpub43_spa_A4_w eb.pdf

Fonseca, M. A. (2010). Treinta años configurando el espacio turístico de Nayarit. Revista de Economia, Sociedad, Turismo y Medio ambiente (RESTMA). Septem Ediciones. España.

Hassan, S. S. (2000). Factores determinantes de la competitividad en el mercado en una industria turística sostenible del medio ambiente. Journal of Travel Research (38), 239-245.

Justafre Garcia, Y. (2009). Manejo integrado de las zonas costeras., Disponible en: http://www.eumed.net/librosgratis/2009a/471/Principios\%20que\%20rigen\%20el\%20MIZC.htm

Organización Mundial del Turismo OMT. (2013). Comunicado de prensa, PR No. PR13006, 28 enero 2013. Disponible en: http://media.unwto.org/es/press-release/2013-0129/el-turismo-internacional-mantendra-un-crecimiento-fuerte-en-2013

Orta F, J. (2005). Retos para la competitividad de la industria turística en el Principado de Asturias. Revista de Economia, Sociedad, Turismo y Medio Ambiente (2), 57-63.

Popoca, A., \& Espejel, I. (s/f). Propuesta de una metodología para evaluar playas recreativas con destino turístico. B.C. México: Universidad Autonoma de Baja California. Disponible en: http://www.ileanaespejel.com/uploads/1/1/3/3/11330338/popoca y espejel.pdf

ProCostas. (2008). Definicion y limite de la zona costa marina. Disponible en: http://procostas.org

Programa de Naciones Unidas para el Medio Ambiente (PNUMA). (2012). Manejo integrado de las zonas costeras y gestión sostenible de los manglares de guatemala, honduras y nicaragua: Boletín Enero-Marzo 2012. Disponible en: www.pnuma.org

Puentes Ávila, I. (2013). Evaluación de las características de sustentabilidad y competitividad para el destino turístico de sol y playa Rincón de Guayabitos, Nayarit. Tesis de maestría, Universidad Autónoma de Nayarit, México. 
SEMARNAT et al. Norma Mexicana NMX-AA-120-SCFI-2016. Que establece los requisitos y especificaciones de sustentabilidad de calidad de playas (Cancela a la NMX-AA-120-SCFI-2006. México. en:

https://www.gob.mx/cms/uploads/attachment/file/213866/NMX-AA-120-SCFI-2016.pdf

Secretaría de Medio Ambiente y Recursos Naturales (SEMARNAT). (2011). Política Nacional de Mares y Costas de México. México: SEMARNAT. 